\title{
ARTICLE
}

\section{Disposable Stencil-Printed Carbon Electrodes for Electrochemical Analysis of Sildenafil Citrate in Commercial and Adulterated Tablets}

\author{
Danielly Santos Rocha ${ }^{1, a}$, Habdias Araujo Silva-Neto ${ }^{1, a}$ iD, Laísa Cristina de Oliveira ${ }^{1}$, Shellyda \\ Gonçalves Guimarães Souza1, Mário Henrique Palis Santana², Wendell Karlos Tomazelli \\ Coltro ${ }^{1,3 *} \square$ \\ ${ }^{1}$ Instituto de Química, Universidade Federal de Goiás, Goiânia, GO, 74690-900, Brazil \\ 2Unidade Técnico-Científica, Superintendência Regional da Polícia Federal, Uberlândia, MG, 38408-6630, Brazil \\ ${ }^{3}$ Instituto Nacional de Ciência e Tecnologia de Bioanalítica, Campinas, SP, 13083-861, Brazil \\ ${ }^{a}$ These authors contributed equally to this work.
}

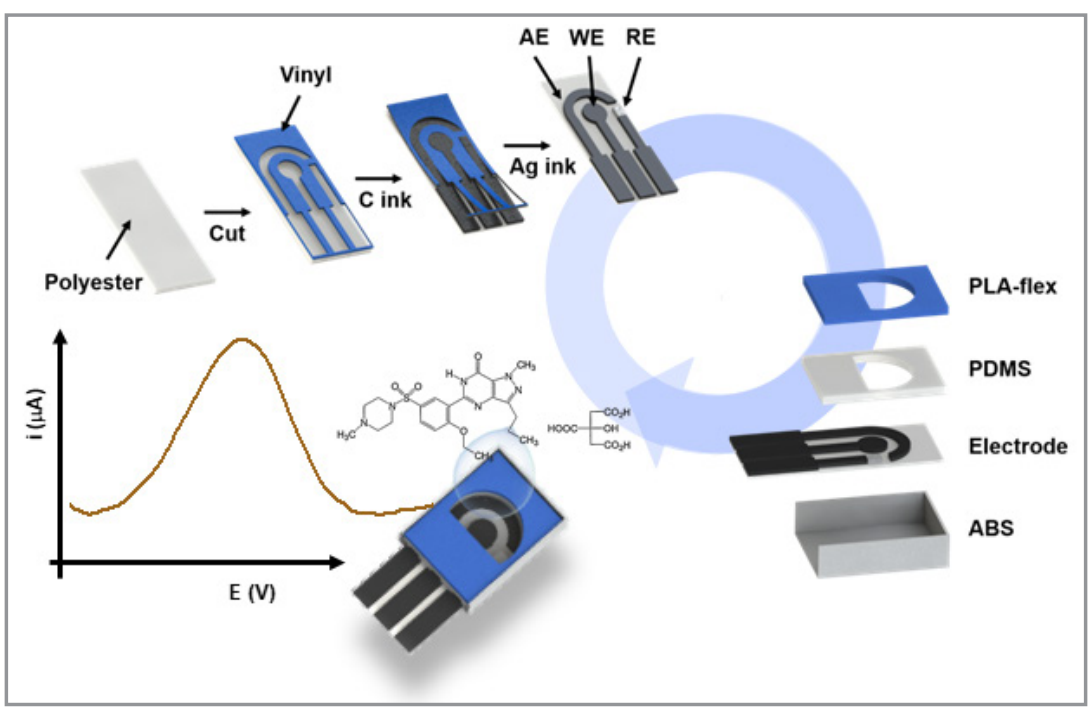

Forensic studies are extremally important to investigate suspected adulterations of consumable products, such as Viagra ${ }^{\circledR}$. This report describes the determination of sildenafil citrate (SC) in commercial and adulterated tablets based on square-wave voltammetry (SWV) measurements using disposable stencil-printed carbon electrodes. The conductive ink used for the manufacture of integrated electrodes was produced by combining graphite powder and glass varnish. To promote a reusable strategy for limiting the geometric area of the electrodes, a 3D-printed holder was constructed. Detailed morphological and electrochemical characterization studies revealed well-defined graphite flakes incorporated on the polymeric substrate and a fast heterogeneous electron-transfer rate constant $\left(\mathrm{Ks}=1.3 \times 10^{-3} \mathrm{~cm} \mathrm{~s}^{-1}\right)$. Based on the analytical performance, a linear behavior was observed in a SC concentration range from 1 to $20 \mu \mathrm{mol} \mathrm{L} \mathrm{L}^{-1}$ with limit of detection equal to $0.2 \mu \mathrm{mol} \mathrm{L}^{-1}$. The selectivity of the proposed method was evaluated and the presence of potentially interfering compounds like phosphate, lactose, paracetamol and tadalafil and no difference higher than $15 \%$ was observed. The analysis of SC was performed in commercial and seized tablets and the achieved values were $50 \pm 1 \mathrm{mg}$

Cite: Rocha, D. S.; Silva-Neto, H. A.; Oliveira, L. C.; Souza, S. G. G.; Santana, M. H. P.; Coltro, W. K. T. Disposable StencilPrinted Carbon Electrodes for Electrochemical Analysis of Sildenafil Citrate in Commercial and Adulterated Tablets. Braz. J. Anal. Chem., 2022, 9 (34), pp 210-228. doi: http://dx.doi.org/10.30744/brjac.2179-3425.AR-65-2021 
for Viagra ${ }^{\circledR}$ tablet, $54 \pm 1 \mathrm{mg}$ for generic formulations $38 \pm 1 \mathrm{mg}$ for seized tablet. In addition, the proposed method offered satisfactory accuracy $(98.2$ - 102.0\%) no noticeable matrix effect. Lastly, considering the achieved results, the use of stencil-printed carbon electrodes and SWV has demonstrated to be a powerful and robust analytical tool for forensic investigations.

Keywords: carbon-based sensors, electrochemical analysis, erectile dysfunction, forensic analysis, Viagra.

\section{INTRODUCTION}

In recent years, the development of compact electrochemical cells combining alternative and/or commercial conductive carbon-based inks and affordable substrates through "do it yourself" protocols has become increasingly popular. In general, electrochemical devices have been fabricated using low-cost and emerging platforms, including paper and plastic materials, and assembled into portable apparatus [1-3]. Besides the low-cost and affordability, instrumental simplicity, ease of operation, reproducibility, portability, and reduced sample consumption are also attractive features which boost the development of alternative electroanalytical devices [4-8]. As well-known, electrochemical sensors are often fabricated by printingbased methods such as inkjet printing [9], screen-printing [10] and stencil-printing [11], which enable the large-scale production with satisfactory fidelity [2]. Cellulose fibers, ceramics and plastics are the most commonly employed substrates to produce printing-based electrodes [2,12,13]. Plastic is particularly advantageous over cellulose and ceramics because it presents interesting physical-chemical and mechanical proprieties, such as robustness, flexibility, durability, hydrophobicity, and optical transparency $[4,8,14]$. Furthermore, different polymeric materials are commercially available including polyester-based substrates.

As mentioned above, polymers are important substrates in the construction of robust printing-based electrodes. Electrochemical sensors have been explored for applications in different fields, including environmental [15], clinical, pharmaceutical, food and forensics sciences and even point-of-care or onsite studies $[2,12,16]$. Considering forensic applications, impact areas such as authenticity screening or detection of adulteration in pharmaceutical compounds are extremely important to society because counterfeit or adulterated formulations are a threat to health and the purchase of these drugs through internet is quite easy $[17,18]$.

According to the World Health Organization (WHO) and the U.S. Food Drug Administration, falsified, adulterated, smuggled or illegally marketed drugs do not comply with specifications and quality standards $[19,20]$. In this sense, the drug may contain the active principal in quantities lower than necessary or the consumer may even be defrauded by the addition of substances that do not have an active effect. It is important to mention that the absence of quality drugs is a recurring problem in the world and exposes people to serious risks, once the inadequate intake of falsified products may cause intoxication or even death [20-22].

Pharmaceutical products associated with erectile dysfunction treatment are one of the classes of drugs most often adulterated in Brazil [17]. Active principles based on tadalafil and sildenafil citrate (SC) are the most commercially popular drugs, in which SC is well-known as Viagra ${ }^{\circledR}$. Their activity principles are based on selective inhibition of the enzyme phosphodiesterase type 5 (PDE-5), which is specific to cyclic guanosine (cGMP) and it is directly related to the regulation of erectile function. This drug has also been reported as an adulterant in food supplements and herbal products aiming to promote improvements in the sexual performance [23-25]. In this way, it is important to investigate possible irregularities in pharmaceutical products based on SC. Selective and robust analytical techniques, such as highperformance liquid chromatography associated to UV detection [26-27], Raman spectroscopy [28] and electrochemistry [29-31] have been explored to aid the forensic authorities [31,36, 37]. In addition, flow injection analysis and batch injection analysis systems coupled with amperometric detection have been also explored as simple as powerful analytical tools for determining SC in erectile dysfunction drugs $[38,39]$. 
As demonstrated by Backes and colleagues [38], the use of carbon-based printed electrodes has offered great analytical performance for accurate determination of SC in commercial drugs including Viagra ${ }^{\circledR}$ and Generics. In this report, we propose a simple combination of disposable stencil-printed carbon electrodes (SPCE) and square-wave voltammetry (SWV) measurements for the determination of SC in commercially available tablets. A compact electrochemical device containing working, reference and auxiliary electrodes was constructed in a single plastic platform using readily affordable materials like glass varnish $[8,40]$ and graphite powder [14]. The electrode surface was characterized using scanning electron microscopy, Raman spectroscopy, contact angle and electrochemical measurements. The forensic feasibility of the proposed approach was demonstrated through the analysis of SC in six commercial tablets and one adulterated sample.

\section{MATERIALS AND METHODS Reagents and materials}

Sildenafil citrate, tadalafil, acetonitrile, potassium ferrocyanide, potassium ferricyanide, potassium chloride, chloride acid, boric acid, phosphoric acid, acetone, paracetamol and lactose were purchased from Sigma-Aldrich (St. Louis, MO, USA) and used as received. Apprehended tablets of SC were provided by the Brazilian Federal Police. Commercial tablets of SC were purchased from a local pharmacy. Stock and standard solutions were prepared using ultrapure water processed through a water purification system (Direct-Q ${ }^{\circledR} 3$, Millipore, Darmstadt, Germany) with resistivity of $18.2 \mathrm{M} \Omega \mathrm{cm}$.

Graphite powder, glass varnish and silver ink were acquired from Fisher Chemical ${ }^{\mathrm{TM}}$ (New Jersey, USA), ACRILEX ${ }^{\circledR}$ (São Paulo, SP, Brazil) and Method Development Co. (Chicago, IL, USA), respectively. Thermoplastic filaments $(\varnothing=1.75 \mathrm{~mm}$ ), acrylonitrile butadiene styrene $(A B S)$ and flexible poly(lactic) acid (Flex-PLA) were provided by 3D Fila (Belo Horizonte, MG, Brazil). Poly(dimethylsiloxane) (PDMS) structures were prepared using a Sylgard 184 elastomer kit (monomer and curing agent) from Dow Corning (Midland, MI, USA). Polyester thermal lamination pouches (250 $\mu \mathrm{m}$ thick) and vinyl adhesive $(125 \mu \mathrm{m}$ thick) were acquired from Yidu Group Co., Ltd (Hsi-Chih, Taipei, Taiwan) and Imprimax ${ }^{\circledR}$ (São Paulo, SP, Brazil), respectively.

\section{Fabrication of the disposable carbon-based electrodes}

The integrated electrochemical cell was manufactured using the stencil-printing technique $[15,41]$. Firstly, two layers vinyl adhesive $(8 \times 11 \mathrm{~cm})$ were combined on the polyester substrate using a spatula tool. The layout of the integrated electrodes was designed using Silhouette Studio software and contained a working electrode (WE; $\varnothing=4 \mathrm{~mm}$ ), reference electrode (RE) and auxiliary electrode (AE). This layout was printed reductively on the vinyl adhesive using a cutting plotter from Silhouette (Belo Horizonte, MG, Brazil). Then, the adhesive structures containing only the electrode designs were removed from the vinyl adhesive/polyester backing using metal tweezers. This step allowed a vinyl stencil to be incorporated with the proposed conductive ink.

The conductive ink was prepared using a procedure adapted from the protocol described by SilvaNeto and coworkers [40]. In brief, the graphite-based ink was based on a mixture composed of $1.5 \mathrm{~g}$ of graphite powder, $1.5 \mathrm{~g}$ of glass varnish (binder) and $4.0 \mathrm{~mL}$ of acetone. To ensure the homogeneity of the ink, these components were mixed under stirring at $1000 \mathrm{rpm}$ for $30 \mathrm{~min}$. Then, the conductive ink was incorporated onto the stencil and polyester substrate using a spatula. After 15 min, the electrode surface was exposed to mechanical polishing process through an alumina sandpaper (1200 mesh). The surface treatment was carried out based on circular mechanical movements. Next, the plastic stencil was manually removed for exposing the integrated electrochemical cell, as illustrated in Figure $1 \mathrm{~A}$. It is important to mention that this amount of conductive ink was enough to manufacture ca. 60 electrochemical cells. To forming a pseudo-reference electrode, the RE was painted with silver ink. The geometric area of the electrochemical devices was delimited using a 3D printed holder, as recently reported [42]. This 3D-printed holder was designed through the SolidWorks ${ }^{\circledR}$ software and printed through a 3D printer model 
open-source from Prusa research (Prague, Czech Republic) via fused deposition modeling employing acrylonitrile butadiene styrene (ABS), flexible polylactic acid (PLA-flex) as the thermoplastic filaments $(\varnothing=1.75 \mathrm{~mm})$. The geometric area delimitation was based on a sandwich assembling of the printed sensing electrodes, PLA-flex, PDMS and ABS films, as demonstrated in Figure 1B.

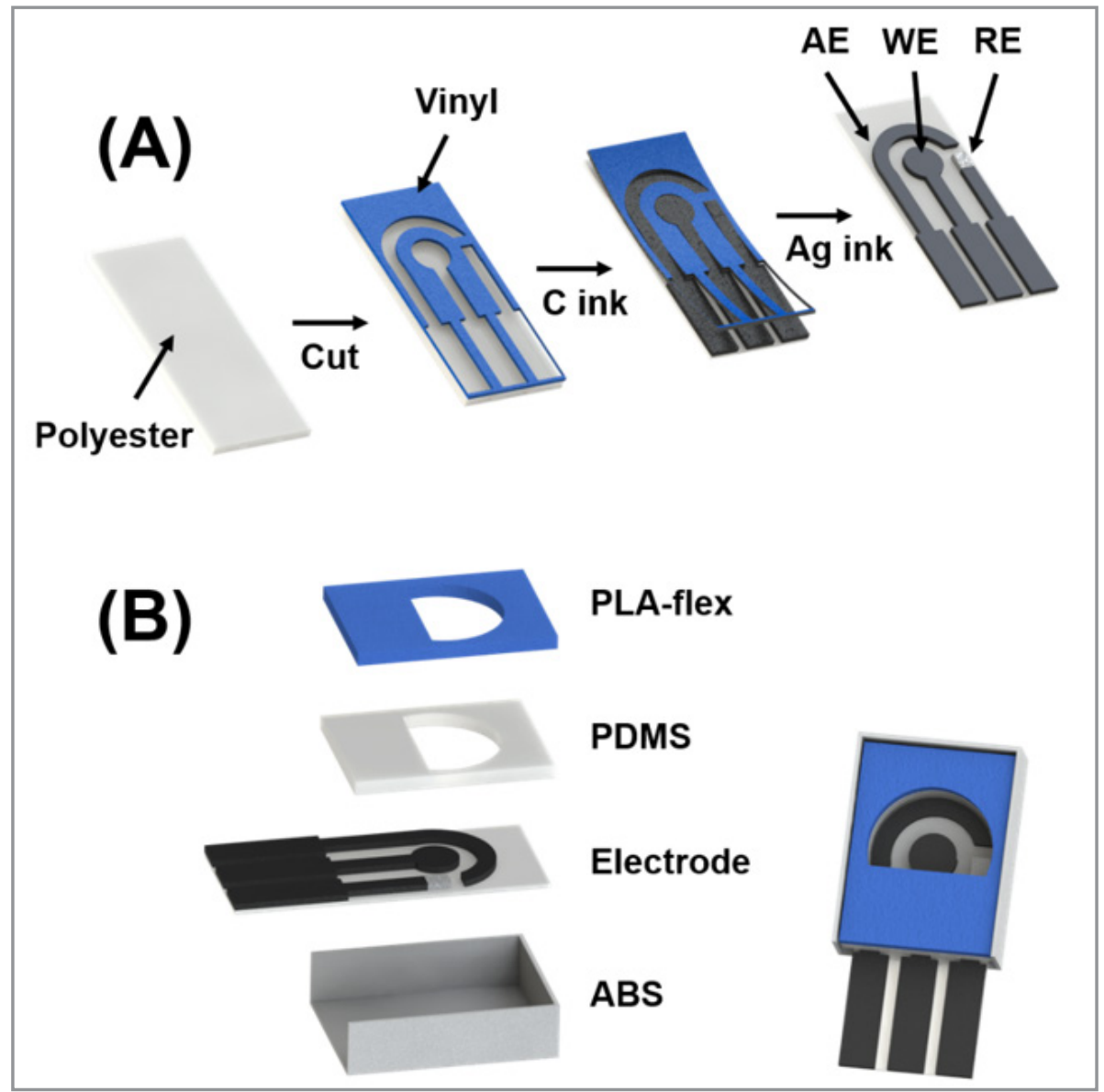

Figure 1. (A) Schematic representation of the stencil-printing method for producing disposable carbon-based electrodes and (B) their assembling in a $3 \mathrm{D}$ printed holder combining thermoplastic materials and PDMS film.

\section{Instrumentation and SWV measurements}

Electrochemical measurements were performed using a portable bipotentiostat/galvanostat, model $\mu$ Stat 400 from DropSens S.L. (Oviedo, Spain) equipped with DropView 2.9 software. The stock solution of SC $\left(5 \mathrm{mmol} \mathrm{L}^{-1}\right)$ was prepared in a mixture of acetonitrile and ultrapure water at the ratio $30: 70(\mathrm{v} / \mathrm{v})$.

For preparing the Viagra $^{\circledR}$ tablet samples, six different products purchased at a local pharmacy (Goiânia, Goiás, Brazil) and one tablet supplied by the Brazilian Federal Police were used. Each tablet was individually ground and solubilized in a mixture of acetonitrile and water $(30: 70 \mathrm{v} / \mathrm{v})$ and exposed to an ultrasound bath for $20 \mathrm{~min}$. Finally, samples were filtered (pore size $=0.22 \mu \mathrm{m}$ ) prior to use. To realize the SWV measurements, standard solutions and tablet samples of SC were prepared in Britton-Robinson buffer $\left(0.03 \mathrm{~mol} \mathrm{~L}^{-1}, \mathrm{pH}=8.0\right)$. The SWV parameters were optimized, and the best results were achieved applying $10 \mathrm{~Hz}$ frequency, $0.025 \mathrm{~V}$ amplitude and $0.004 \mathrm{~V}$ step ranging from 0.9 to $1.5 \mathrm{~V}$ vs Ag. All electrochemical experiments were performed at room temperature $\left(25 \pm 2{ }^{\circ} \mathrm{C}\right)$. 


\section{Characterization}

The surface morphology, the structural characteristics as well as the faradaic performance of the proposed SPCE were characterized by scanning electron microscopy (SEM), Raman spectroscopy, contact angle (CA) and cyclic voltammetry (CV) measurements. SEM analyses were performed with a JEOL microscope (model JSM, 6610, Waltham, MA, USA). Raman spectra were obtained with a confocal Raman spectrometer (model Horiba LabRAM HR Evolution, HORIBA France SAS) using a laser of wavelength $532 \mathrm{~nm}$ and a spot size of $2.6 \mu \mathrm{m}$. CA experiments were carried out by a Xiaomi Redmi note 10 smartphone camera fixed to a modular 3D-printed holder [43] and ImageJ software. CV measurements were recorded in $1.0 \mathrm{mmol} \mathrm{L}^{-1}\left[\mathrm{Fe}(\mathrm{CN})_{6}\right]^{4-/ 3-}$ prepared in $0.1 \mathrm{~mol} \mathrm{~L}^{-1} \mathrm{KCl}$ at scanning rates ranging from 10 to $100 \mathrm{mV} \mathrm{s}^{-1}$. These electrochemical experiments were realized with the goal of estimating the standard heterogeneous rate constant $\left(\mathrm{K}_{\mathrm{S}}\right)$ based on the Nicholson method [44].

\section{RESULTS AND DISCUSSION Fabrication of the SPCES}

The stencil-printing technique is one of the most versatile techniques for manufacturing electrochemical sensors [45]. This fabrication strategy is particularly advantageous because it can use portable apparatus and low-cost resources, thus offering ability of creating microstructures in large scale with satisfactory fidelity [2,11]. The instrumentation required to prepare the masks by cutting plotter can be acquired for ca. USD 200. Also, this technology can enable the creation of alternative "do it yourself" conductive inks, which further reduces the cost of preparing components of the target analytical devices. In general, the electrochemical performance of SPCEs manufactured with alternative inks allows appreciable faradaic results with a huge potential for applications in different fields.

For the development of the alternative conductive ink, graphite powder was used as the conductive material and glass varnish as binder, as reported in a recent study [40]. The glass varnish is composed of an alkyd resin, which allows the formation of a solid composite with excellent conductive properties when incorporated with graphite flakes. Recently, Pradela et al. [8] manufactured carbon-based electrodes combining glass varnish and graphite powder on a PET substrate. The authors used permanent adhesive tape to delimit the geometric area of the electrochemical cell. As proof of concept, the proposed electrochemical cell was explored to detect estriol hormones in tap water and pharmaceutical formulation samples. In this current study, the SPCE was fabricated through a stencil-printing technique using these well-known low-cost materials. However, we used a reusable 3D-printed holder to delimitate the geometric area of the SPCE aiming drug analysis for forensic applications.

\section{Morphological, structural, and electrochemical characterization}

To evaluate the morphology and surface characteristics of the carbon-based material proposed herein, SEM images and CA measurements were recorded for WE surface. Figures 2A and 2B show SEM images recorded at different magnifications (30,500 and 1000x) and captured images for CA measurements, respectively. 


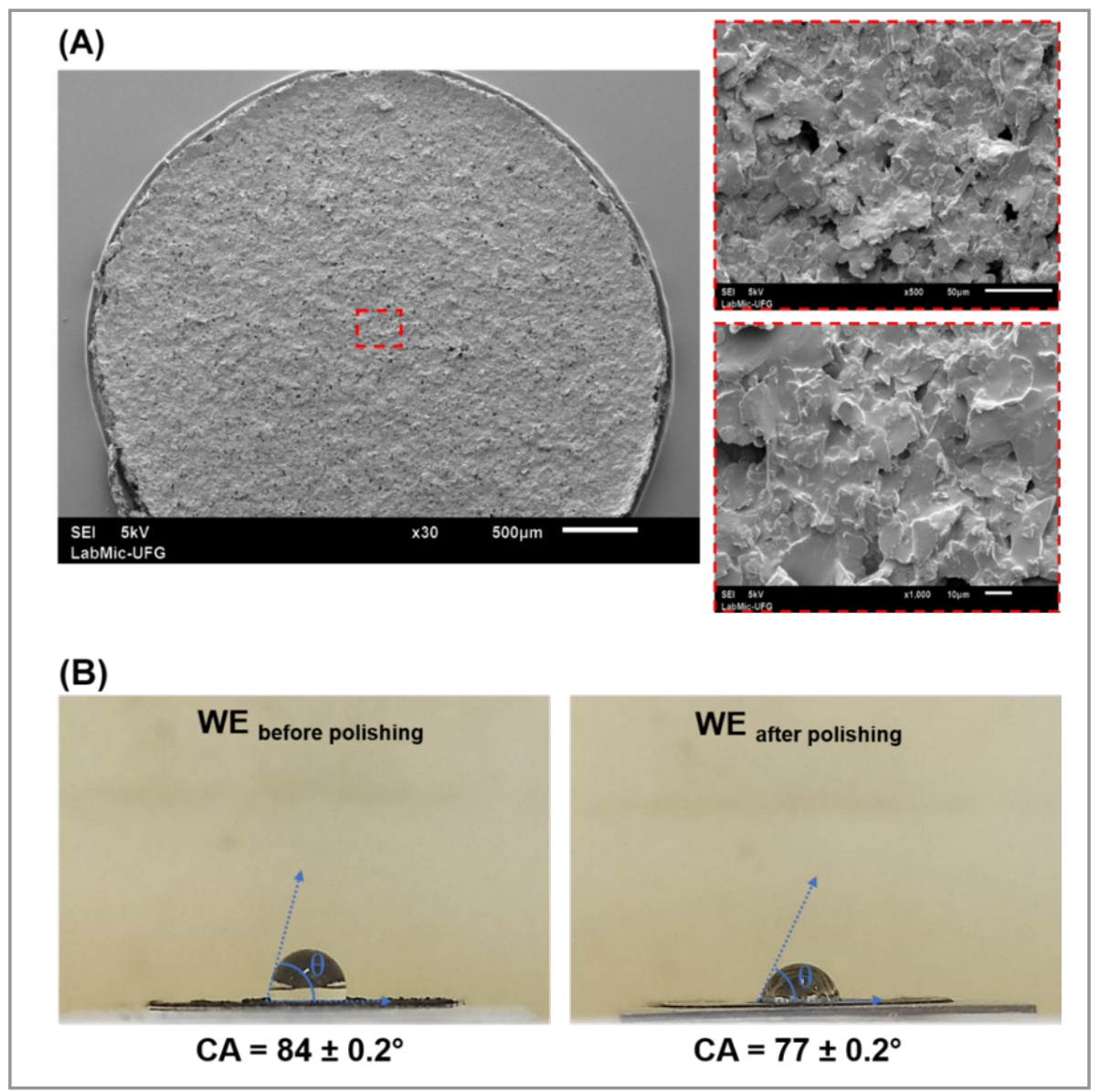

Figure 2. (A) SEM captured imagens of the WE and (B) CA measurements to WE surface before and after the polishing process.

As it can be seen, the conductive material presents a surface with graphite flakes homogenously and extensively incorporated on the polyester surface with an absence of microcracks on the carbon-based flakes. This characteristic suggests that the transfer of the conductive ink to the substrate surface was successfully achieved. Based on the recorded images, the size of the graphite flakes and the real diameter of the WE were estimated to be $9 \pm 4 \mu \mathrm{m}$ and $3.7 \pm 0.2 \mathrm{~mm}$, respectively.

The calculated value for the WE diameter through SEM images was compared to the theoretical dimension $(\varnothing=4 \mathrm{~mm}$ ) and it revealed satisfactory fidelity ( 91\%). Regarding the physical characteristics of the conductive material adhered to the substrate, it was noticed that the binder appeared partially to cover the conductive graphite flakes. For this reason, a mechanical polishing step was added to the preparation method aiming to remove the excess binder and expose more graphite flakes on the surface. This strategy was adopted to enhance the electrochemical performance of the proposed SPCE. The electrochemical responses achieved before and after polishing pre-treatment are summarized in Figure S1, available in the electronic supplementary information (ESI).

Likewise SEM images, CA measurements were obtained for the proposed SPCE surface before and after the polishing process. As denoted in Figure 2, the captured images of the electrode surface before and after mechanical polishing revealed CA values equal to $84 \pm 0.2^{\circ}$ and $77 \pm 0.2^{\circ}$, respectively. These results suggest that the excess hydrophobic material was satisfactorily removed by mechanical polishing. In addition, Cumba et al. [46] demonstrated that the mechanical polishing process on screen-printed carbon electrodes surface promotes the insertion of carbon-oxygen groups, which can improve the electron transfer rate kinetics. For this reason, the noticeable improvement observed for the electrochemical response 
is probably associated to a lower repulsion to the target analyte upon the electrode solid surface. It is important to mention that carbon-based electrodes with hydrophilic properties may have greater potential in biofunctionalization, which can be interesting for applications involving sensors and biosensors.

Raman spectra provide fundamental information of the $\mathrm{sp}^{2}$ and $\mathrm{sp}^{3}$ carbon-based microstructures [47]. For this reason, the carbon-based ink incorporated on the plastic structure was evaluated using unpolished electrodes. Figure 3A shows the Raman spectrum with bands D, G and 2D at 1350, 1586 and $2702 \mathrm{~cm}^{-1}$, respectively.

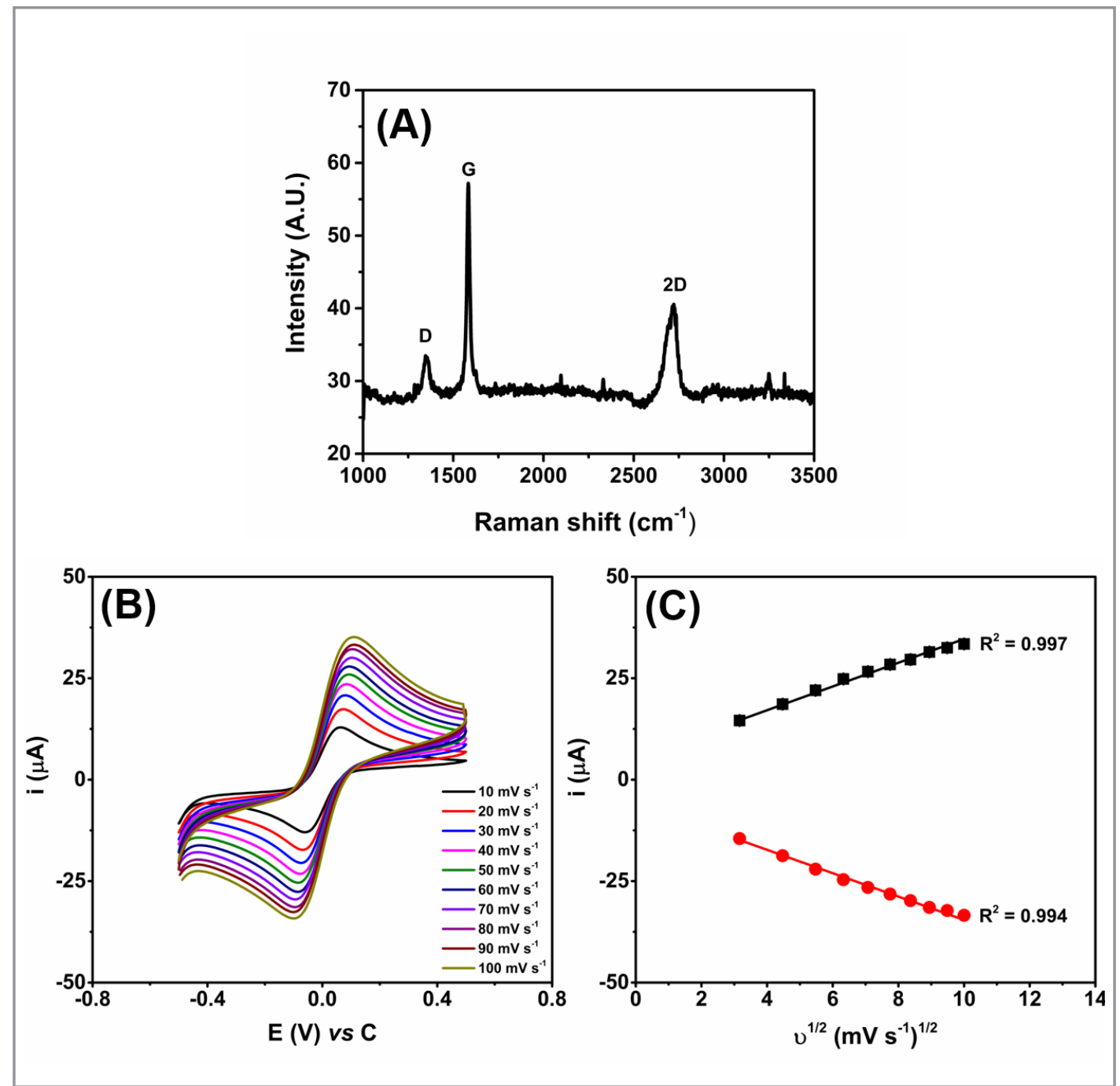

Figure 3. (A) Raman spectra ranging from 1000 to $3500 \mathrm{~cm}^{-1}$, (B) cyclic voltammograms and (C) peak current $v s$ scanning rate ${ }^{1 / 2}$ plots involving electrochemical experiments in the presence of 1.0 $\mathrm{mmol} \mathrm{L}-1\left[\mathrm{Fe}(\mathrm{CN})_{6}\right]^{4-13-}$ prepared in $0.1 \mathrm{~mol} \mathrm{~L}^{-1} \mathrm{KCl}$ at scanning rates ranging from 10 to $100 \mathrm{mV} \mathrm{s}^{-1}$.

Based on the recorded intensity of $D$ and $G$ bands $\left(I_{D}\right.$ and $I_{G}$, respectively), the $I_{D} / I_{G}$ ratio was calculated and the resulting value was 0.19 . The obtained response provides structural defects information involving the graphite flakes incorporated on polymeric substrate. When comparing this value with that reported in the literature for pure graphite (0.014) [47], it is possible to observe a drastic increase in the structural defects in the carbon microstructures distributed on the SPCE surface. This behavior may be associated with the incorporation of the graphite flakes in the amorphous polymeric material used as binder, as 
recently reported [48]. It is important to highlight that carbon-based microstructures with high numbers of structural defects have been used as material to manufacture of electrochemical sensors. Examples that are gaining prominence are the carbon allotropes such as graphene, graphite and carbon black. These materials present considerable structural defects, with $I_{D} / I_{G}$ ratio ranging from 0.16 to $1.0[47,49,50]$.

The electrochemical performance of the proposed electrochemical cell was investigated using $\left[\mathrm{Fe}(\mathrm{CN})_{6}\right]^{4-13-}$ as redox probe aiming to evaluate the kinetic mass transfer (considering one electron) on the heterogenous electrolyte support/SPCE interface. Figure 3B depicts the recorded cyclic voltammograms at scanning rates ranging from 10 to $100 \mathrm{mV} \mathrm{s}^{-1}$. The peak-to-peak separation $(\Delta \mathrm{Ep})$ values calculated for low $\left(10 \mathrm{mV} \mathrm{s}^{-1}\right)$ and high $\left(100 \mathrm{mV} \mathrm{s}^{-1}\right)$ scanning rates were $114 \pm 6$ and $195 \pm 10 \mathrm{mV}$, respectively $(n=3)$. A linear behavior $\left(R^{2}=0.99\right)$ was observed for the peak current intensity versus square root of the scanning speed rate (Figure $3 \mathrm{C}$ ), thus suggesting that the mass transfer is diffusion-controlled in a quasireversible process. For this reason, the standard heterogeneous rate constant (Ks) was estimated based on the Nicholson method $(n=3)$. The achieved value was $1.3( \pm 0.2) \times 10^{-3} \mathrm{~cm} \mathrm{~s}^{-1}$ and it is good agreement with other reports found in the literature for carbon-based electrodes [44,51,52], thus highlighting the high electrochemical performance of the proposed SPCE. It is important to mention that the current study has successfully demonstrated for the first time the Ks value for an electrode manufactured using glass varnish-based carbon conductive ink.

\section{D-printed holder, repeatability and reproducibility}

A reusable 3D-printed holder was fabricated and combined with the electrode aiming to simplify the manipulation of the hydrophobic barriers on the SPCE. This step is important to promote the isolation of the electrical contacts and to delimit the electrode geometric area. To demonstrate that the present strategy is similar to non-reusable and traditional methods, a comparative study was performed using the 3D-printed holder and other reported strategies [4,48]. The CV technique was used in the presence of $\left[\mathrm{Fe}(\mathrm{CN})_{6}\right]^{4-/ 3-}$ using the SCPE combined with the present hydrophobic barrier, nail polish binder and laminated thermoplastic polyester. Figures $4 \mathrm{~A}$ and $4 \mathrm{~B}$ show the voltammograms and the resulting peak current intensities, respectively.
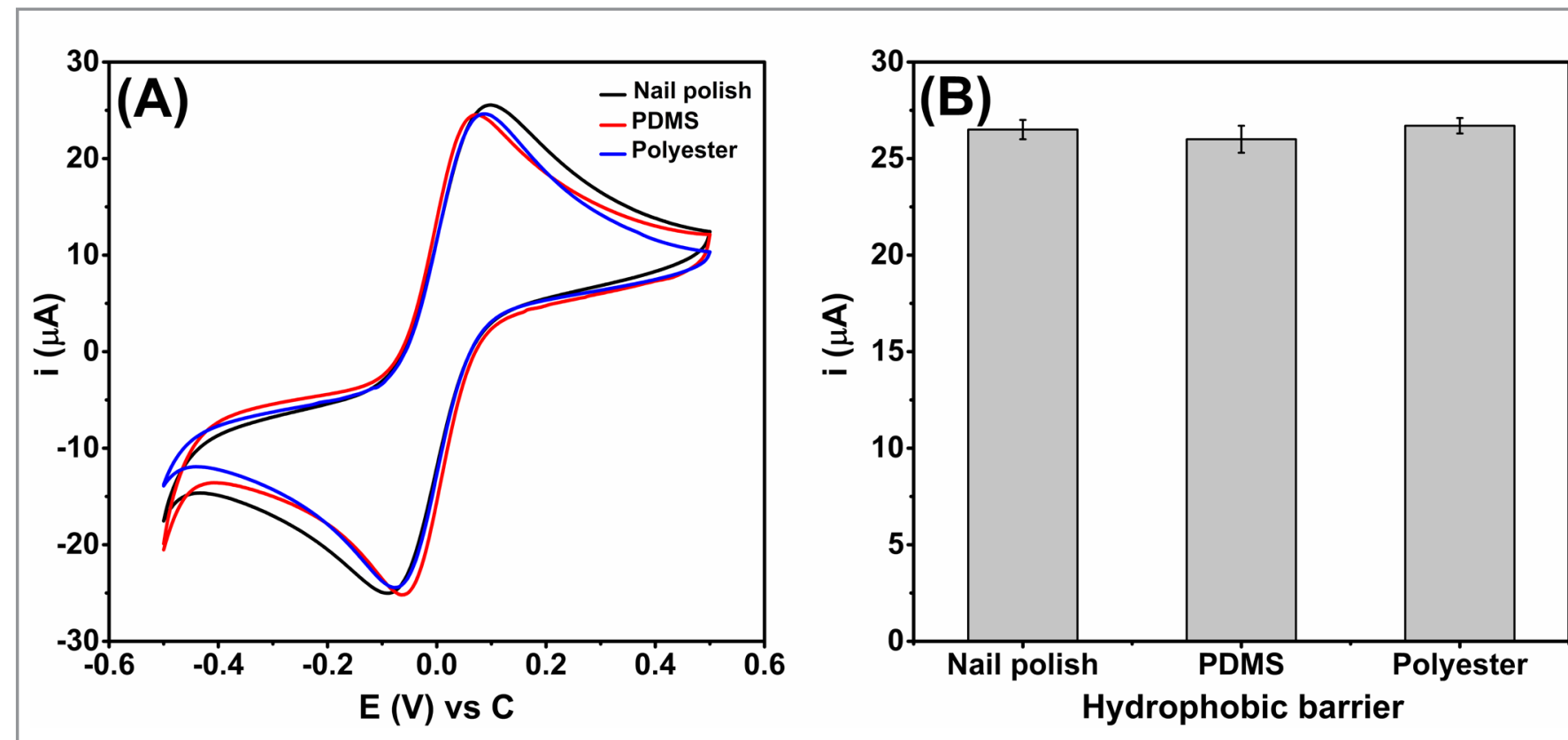

Figure 4. (A) Cyclic voltammograms and (B) current peak intensities recorded for a redox probe composed of 1.0 $\mathrm{mmol} \mathrm{L}-1\left[\mathrm{Fe}(\mathrm{CN})_{6}\right]^{4-13-}$ prepared in $0.1 \mathrm{~mol} \mathrm{~L}^{-1} \mathrm{KCl}$ using the proposed SPCE combined with hydrophobic barriers like nail polish, PDMS and polyester. CV conditions: scanning rate $=50 \mathrm{mV} \mathrm{s}^{-1}$ at potential window ranging from -0.5 to $0.5 \mathrm{~V}$ vs $\mathrm{C}$. 
As it can be seen in Figure 4, the obtained anodic peak current intensities did not change significantly between the PDMS, polyester and the 3D-printed support hydrophobic barrier. The electrochemical results in each case presented a relative standard deviation (RSD) lower than $1.5 \%$. It is important to state that the 3D-holder associated with stencil-printing technology made use of a disposable SPCE and a reusable hydrophobic barrier to simplify the day-to-day use.

In addition, it is important to mention that the creation of hydrophobic barriers based on nail polish and thermal lamination requires manual painting and heating steps, respectively. Both manual protocols are instrumentally simple, however, they are dependent on visual perception and can be susceptible to low reproducibility during the fabrication step. When nail polish is used, for example, the binder invasion into working structure leads to the formation of different electroactive areas. In a similar way, the thermal stress used in the thermosensitive barrier process can create micro-fissures in the graphite surface, thus negatively affecting their electrical properties. On the other hand, the PDMS hydrophobic barrier is reusable as well as the 3D printed holder, i.e., once successfully printed, they can be used repeatedly [42]. This strategy is based on the formation of a sandwich arrangement (ABS support, electrode, PDMS film and PLA-Flex), which can be easily assembled or disassembled through compression and decompression of the 3D printed holder, respectively.

The repeatability and reproducibility of the SPCE fabrication protocol was also investigated through electrochemical measurements and the achieved data are summarized in Figure S2, available in the ESI. The obtained RSD values for repeatability and reproducibility were $1.4 \%(n=10)$ and $7.8 \%(n=5)$, respectively. The achieved results are comparable with those reported in studies on carbon-based electrodes constructed via screen-printing and pencil-drawn methods [5,53].

\section{Analytical performance and forensic application}

Forensic investigations by security and product control organizations are fundamental for human society [16]. Inspection of the quality of commercial products is one of the most important ability of forensic police, mainly in locations close to airports, docks and highways [16]. Products considered to be in high circulation in society and with considerable aggregate value, such as SC (Viagra ${ }^{\circledR}$ ), are manufactured and sold illegally. These irregular formulations either have an absence or minimal presence of the expected active ingredient, or contain inactive substances or those harmful to human health [54]. For this reason, the manufactured SPCE was used in the analysis of SC in tablets of suspect origin.

To obtain a satisfactory analytical performance, important chemical conditions and electrochemical parameters were carefully evaluated, such as the $\mathrm{pH}$ and SWV parameters including frequency, amplitude and step. As can be seen in Figure S3, the potential (vs Ag) and peak current involved in the redox activity of $\mathrm{SC}$ are strongly influenced by the $\mathrm{pH}$ range of the supporting electrolyte solution. It is well-known that when buffer $\mathrm{pH}$ increases, the potential (vs Ag) changes to less positive values, as previously reported to the electrochemical cell based on graphite electrode vs Ag as pseudo reference electrode [38]. In addition, it was possible to observe a noticeable improvement of the electrochemical oxidation response to SC when the analyte solution is prepared in $\mathrm{BR}$ buffer at $\mathrm{pH} 8$. In this way, the chemical conditions mentioned above were chosen for the subsequent electrochemical experiments. Likewise, it is well-known that the operating parameters such as frequency, step and amplitude influence on SWV responses. Then, these conditions were also investigated and the recorded results are displayed in Figures S3-S6 (available in the ESI). The optimized values revealed a noticeable gain in the peak current magnitude so that the chosen parameters were $10 \mathrm{~Hz}, 0.025 \mathrm{~V}$ e $0.004 \mathrm{~V}$ for frequency, amplitude and step, respectively. The best achieved conditions and parameters are summarized in Table I. 
Table I. Evaluated and optimized conditions for the SWV detection of sildenafil citrate

\begin{tabular}{lccc}
\hline Parameter & Evaluated range & Optimized value & Unit \\
\hline $\mathrm{pH}$ & $2 ; 4 ; 8$ & 8 & - \\
Frequency & $5 ; 10 ; 15$ & 10 & $\mathrm{~Hz}$ \\
Amplitude & $0.025 ; 0.050 ; 0.075$ & 0.025 & $\mathrm{~V}$ \\
Step & $0.002 ; 0.003 ; 0.004$ & 0.004 & $\mathrm{~V}$ \\
\hline
\end{tabular}

The analytical performance of the proposed SPCE was studied under the optimized conditions. As presented in Figure 5, a linear behavior $\left(R^{2}=0.990\right)$ was observed in the SC concentration range from 1 to $20 \mu \mathrm{mol} \mathrm{L}{ }^{-1}$. Considering the data presented in Figure 5B, the limit of detection (LOD) was estimated based on the ratio between three times the standard deviation for the blank signal and the slope of the analytical curve (LOD $=3.0 \times \mathrm{SD}_{\text {blank }}$ /slope). The obtained value was $0.2 \mu \mathrm{mol} \mathrm{L}^{-1}(\mathrm{n}=3)$ and this value is in the same magnitude order than those LODs reported in other studies employing glassy carbon [36] and boron-doped diamond [33] electrodes. It is important to emphasize that the LOD achieved using SPCE is suitable for forensic studies aiming the detection of SC since its analytical performance was considered satisfactory when compared to other electrochemical methods based on carbon-based electrodes $[31,33,35,36,38]$. The analytical parameters found in this current study were compared to reported electrochemical methods and they are summarized in Table SI (available in the ESI).

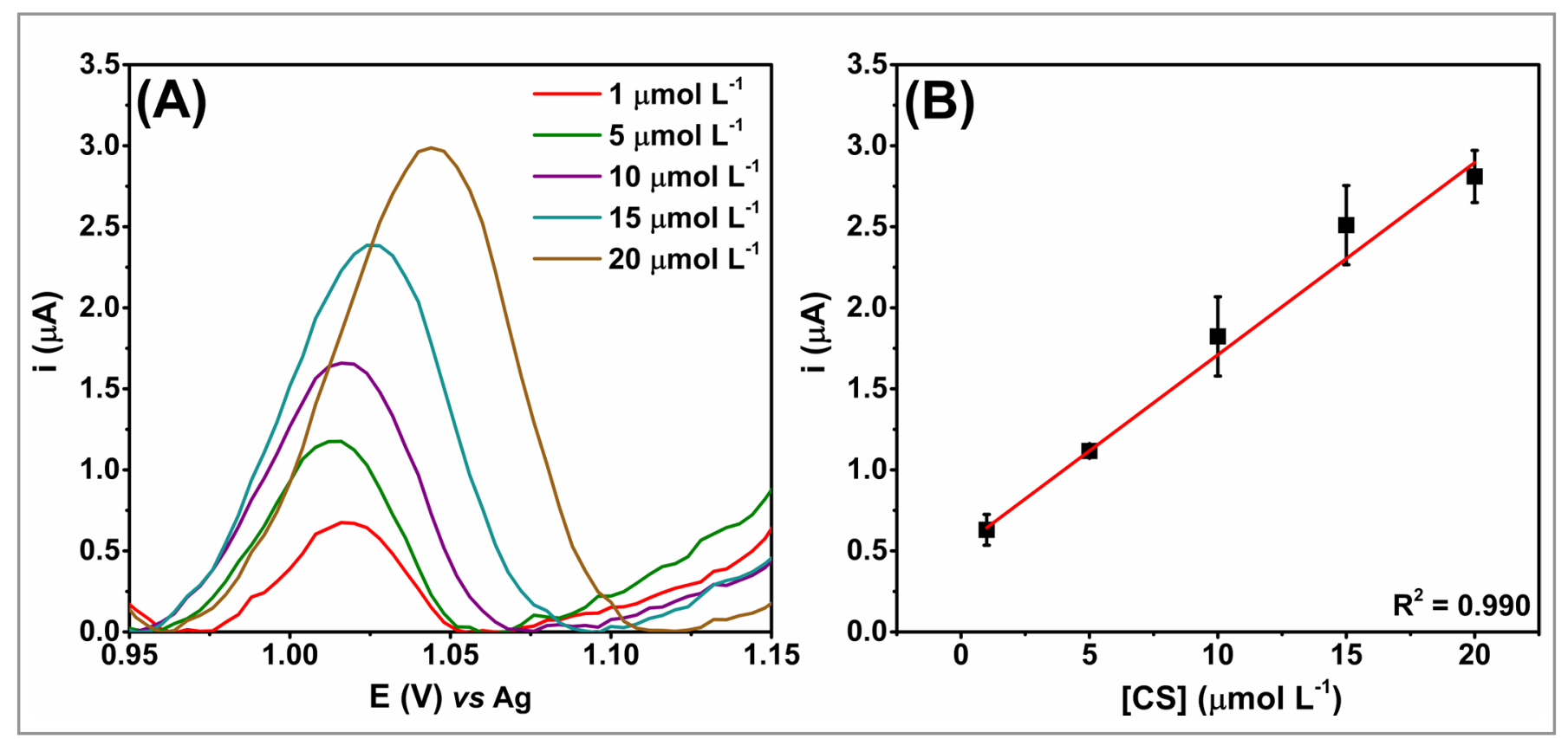

Figure 5. (A) SWV responses and (B) the resulting analytical curve obtained for standard solutions of SC prepared at different concentrations (1 to $20 \mu \mathrm{mol} \mathrm{L}-1)$. Standard solutions were prepared in $0.03 \mathrm{~mol} \mathrm{~L}^{-1}$ Britton-Robinson buffer at $\mathrm{pH}$ 8. Linear regression equation: $\mathrm{i}(\mu \mathrm{A})=0.52+0.118[\mathrm{SC}]$.

\section{Interference analyses}

Pharmaceutical formulations are manufactured using the active principle and multiple other compounds to promote proper digestibility and functional performance. However, when considering adulterated tablets, 
the interference possibilities are complex. For this reason, the selectively of the present method was investigated using compounds used as tablet excipients and other drugs, including those used for the treatment of erectile dysfunction (phosphate, lactose, paracetamol and tadalafil).

Electrochemical measurements were performed in the absence and presence of the possible interfering compounds considering a ratio of 10:1 (SC/interfering). The recorded CV measurements are presented in Figure S7. Based on achieved results, the percentage of interference causing an electrochemical signal increase in the presence of phosphate, lactose, tadalafil and paracetamol ranged from 6 to $14 \%$. Electrochemical analysis of SC in the presence of tadalafil showed the greatest signal variation (14\%). This level is statistically acceptable [55] and it can be associated with the similar oxidation potential $(\sim 1.0 \mathrm{~V}$ vs Ag). However, this oxidation potential can be strongly affected by the $\mathrm{pH}$ of the prepared samples [56].

\section{Analysis of SC in commercial and seized tablets}

The proposed SPCE devices were then explored to determine SC content in commercial samples including Viagra ${ }^{\circledR}(\# 1)$ and six different suppliers of generic products (\#2, \#3, \#4, \#5 and \#6). In addition, the SC content was also determined in one sample seized and donated by the federal police (\#7). The results are displayed in Table II.

Table II. Summary of the SC content in commercial and seized tables using SPCE and SWV measurements $(n=3)$

\begin{tabular}{ccc}
\hline Samples & Labeled $(\mathbf{m g})$ & Found $(\mathbf{m g})$ \\
\hline$\# 1$ & 50 & $50 \pm 1$ \\
$\# 2$ & 50 & $54 \pm 6$ \\
$\# 3$ & 50 & $54 \pm 4$ \\
$\# 4$ & 50 & $54 \pm 6$ \\
$\# 5$ & 50 & $52 \pm 1$ \\
$\# 6$ & 50 & $54 \pm 1$ \\
$\# 7$ & 50 & $38 \pm 1$ \\
\hline
\end{tabular}

As it can be seen in Table II, the achieved data using SPCE were compared to the labelled content by different suppliers. For samples \#1-6, the differences observed ranged between 2 and $8 \%$. On the other hand, the SC content obtained for sample \#7 was ca. $22 \%$ lower than the labeled value. This was somehow expected since this sample was seized by the Federal Police due to suspected adulteration. The obtained data was statistically compared through t-test (95\% significance) and the calculated t and t-critical values were -0.38 and 2.44 , respectively. Considering the paired t-test, it can be inferred that the results obtained for samples \#1-6 did not reveal statistical differences between the achieved and labeled values at confidence level of $95 \%$. On the other hand, the paired t-test confirmed (calculated $t$ value lower than t-critical) that the obtained SC values for seized tablet (sample \#7) was lower than the expected content thus suggesting the adulteration of the active principle amount. Based on the achieved data, it can be inferred that the proposed SPCE emerges as huge potential as analytical tool for forensic investigations.

The accuracy of the proposed SWV experiments using SPCE was investigated through recovery experiments. For this purpose, a solution containing SC ((50 mg per tablet) sample \#1) was diluted to $5 \mu \mathrm{mol} \mathrm{L} \mathrm{L}^{-1}$ and then spiked with three different levels of SC standard solution $\left(5,10\right.$ and $\left.15 \mu \mathrm{mol} \mathrm{L} \mathrm{L}^{-1}\right)$. The achieved results of the recovery experiment are shown in Table III. The recovery studies demonstrated 
values ranging from 98.2 to $102.0 \%(n=3)$, which suggest that the proposed analytical procedure did not suffer significant interference from the tablet matrix. In addition, the obtained percentages were within the range allowed by the regulatory agencies [55] and they are similar to the values reported in other studies dedicated to the determination of SC in commercial tablets $[37,57]$.

Table III. Standard addition method for quantification of SC and recovery values considering to SWV experiments $(n=3)$

\begin{tabular}{cccc}
\hline \multirow{2}{*}{ Spiking level } & \multicolumn{2}{c}{ Sildenafil citrate $\left(\mu \mathrm{mol} \mathrm{L}^{-1}\right)$} & \multirow{2}{*}{ Recovery $(\%)$} \\
\cline { 2 - 3 } & Added & Found & 102.0 \\
$\# 1$ & 5 & $5.1 \pm 0.1$ & 101.3 \\
$\# 3$ & 10 & $10.2 \pm 0.4$ & 98.2 \\
\hline
\end{tabular}

\section{CONCLUSIONS}

In summary, simple and disposable stencil-printed electrodes have demonstrated great feasibility for forensic investigations based on voltametric determination of sildenafil citrate in commercial and seized tablets. The proposed device was fabricated using affordable materials and assembled in a sandwich arrangement composed of a 3D-printed piece, a PDMS film and a PLA-flex, offering robustness and reproducibility. The mechanical polishing pre-treatment of the electrode surface was essential to expose more conductive particles allowing to achieve noticeable improvements on the electrochemical performance. The proposed approach revealed to be a promising analytical tool for forensic screening since it has ensured accurate analysis of SC in commercial and seized tablets. Future studies will focus on a complete validation of the proposed approach involving a larger and more representative sampling and a comparison with a reference analytical technique.

\section{Conflicts of interest}

The authors declare no conflict of interest.

\section{Acknowledgements}

The authors would like to thank CAPES [grant 3363/2014], CNPq [grants 426496/2018-3, 308140/2016-8 and 307554/2020-1] and INCTBio [grant 465389/2014-7] for the financial support and granted scholarships. The authors acknowledge the Multi-user Laboratory of high-resolution microscopy (LabMic/UFG) for using their facilities during SEM analysis. Lastly, we thank Professor Dr. Janegitz, B. C. for providing the graphite powder.

\section{REFERENCES}

1. Dossi, N.; Terzi, F.; Piccin, E.; Toniolo, R.; Bontempelli, G. Electroanalysis, 2016, 28 (2), pp 250-264 (https://doi.org/10.1002/elan.201500361).

2. Ataide, V. N.; Mendes, L. F.; Gama, L. I . L. M.; de Araujo, W. R.; Paixão; T. R. L. C. Anal. Methods, 2020, 12, pp 1030-1054 (https://doi.org/10.1039/c9ay02350j).

3. de Moraes, N. C.; da Silva, E. N. T.; Petroni, J. M.; Ferreira, V. S.; Lucca, B. G Electrophoresis, 2019, 41 (5-6), pp 278-286 (https://doi.org/10.1002/elps.201900270).

4. Foster, C. W.; Metters, J. P.; Banks, C. E. Electroanalysis, 2013, 25, pp 2275-2282 (https://doi.org/ 10.1002/elan.201300274). 
5. Camargo, J. R.; Andreotti, I. A. A.; Kalinke, C.; Henrique, J. M.; Bonacin, J. A.; Janegitz, B. C. Talanta, 2020, 208, 120458 (https://doi.org/10.1016/j.talanta.2019.120458).

6. Petroni, J. M.; Lucca, B. G.; Ferreira, V. S. Electroanalysis, 2017, 29 (7), pp 1762-1771 (https://doi. org/10.1002/elan.201700117).

7. Sameenoi, Y.; Mensack, M. M.; Boonsong, K.; Ewing, R.; Dungchai, W.; Chailapakul, O.; Cropek, D. M.; Henry, C. S. Analyst, 2011, 136 (15), pp 3177-3184 (https://doi.org/10.1039/c1an15335h).

8. Pradela-Filho, L. A.; Andreotti, I. A. A.; Carvalho, J. H. S.; Araújo, D. A. G.; Orzari, L. O.; Gatti, A.; Takeuchi, R. M.; Santos, A. L.; Janegitz, B. C. Sens. Actuators B Chem., 2020, 305, 127433 (https:// doi.org/10.1016/j.snb.2019.127433).

9. Tortorich, R. P.; Shamkhalichenar, H.; Choi, J. W. Appl. Sci., 2018, 8 (2), 288 (https://doi.org/10.3390/ app8020288).

10. Lamas-Ardisana, P. J.; Casuso, P.; Fernandez-Gauna, I.; Martínez-Paredes, G.; Jubete, E.; Añorga, L.; Cabañero, G.; Grande, H. J. Electrochem Commun., 2017, 75, pp 25-28 (https://doi.org/10.1016/j. elecom.2016.11.015).

11. Kava, A. A.; Beardsley, C.; Hofstetter, J.; Henry, C. S. Anal. Chim. Acta, 2020, 1103, pp 58-66 (https:// doi.org/10.1016/j.aca.2019.12.047).

12. Adkins, J.; Boehle, K.; Henry, C. Electrophoresis, 2015, 36, pp 1811-1824 (https://doi.org/10.1002/ elps.201500084).

13. Pradela-Filho, L. A.; Araújo, D. A. G.; Takeuchi, R. M.; Santos, A. L. Electrochim. Acta, 2017, 258, pp 786-792 (https://doi.org/10.1016/j.electacta.2017.11.127).

14. Andreotti, I. A. A.; Orzari, L. O.; Camargo, J. R.; Faria, R. C.; Marcolino-Junior, L. H.; Bergamini, M. F.; Gatti, A.; Janegitz, B. C. J. Electroanal. Chem., 2019, 840, pp 109-116 (https://doi.org/10.1016/j. jelechem.2019.03.059).

15. Martín-Yerga, D.; Álvarez-Martos, I.; Blanco-López, M. C.; Henry, C. S.; Fernández-Abedul, M.T. Anal. Chim. Acta, 2017, 981, pp 24-33 (https://doi.org/10.1016/j.aca.2017.05.027).

16. de Araujo, W. R.; Cardoso, T. M. G.; da Rocha, R. G.; Santana, M. H. P.; Muñoz, R. A. A.; Richter, E. M.; Paixão, T. R. L. C.; Coltro, W. K. T. Anal. Chim. Acta, 2018, 1034, pp 1-21 (https://doi.org/10.1016/j. aca.2018.06.014).

17. Jung, C. R.; Ortiz, R. S.; Limberger, R.; Mayorga, P. Forensic Sci. Int., 2012, 216 (1-3), pp 92-96 (https://doi.org/10.1016/j.forsciint.2011.09.002).

18. Park, M.; Ahn, S. Forensic Sci. Int., 2012, 57 (6), pp 1637-1640 (https://doi.org/10.1111/j.15564029.2012.02164.x).

19. Shinde, S. R.; Bhavsar, K.; Kimbahune, S.; Khandelwal, S.; Ghose, A. Annu. Int. Conf. IEEE Eng. Med. Biol. Soc., 2020, pp 6155-6158 (https://doi.org/10.1109/EMBC44109.2020.9176419).

20. Orubu, E. S. F.; Ching, C.; Zaman, M. H.; Wirtz, V. J. J. Pharm. Policy Pract., 2020, 13 (1), pp 1-10 (https://doi.org/10.1186/s40545-020-00208-4).

21. Sanada, T.; Yoshida, N.; Matsushita, R.; Kimura, K.; Tsuboi, H. Forensic Sci. Int., 2020, 307, 110143 (https://doi.org/10.1016/j.forsciint.2020.110143).

22. Sanada, T.; Yoshida, N.; Kimura, K.; Tsuboi, H. Pharmacy, 2020, 9 (1) (https://doi.org/10.3390/ pharmacy9010003).

23. Patel, D. N.; Li, L.; Kee, C. L.; Ge, X.; Low, M. Y.; Koh, H. L. J. Pharm. Biomed. Anal., 2014, 87, pp 176-190 (https://doi.org/10.1016/j.jpba.2013.04.037).

24. Kass, D. A.; Champion, H. C.; Beavo, J. A. Circulation Research, 2007,101 (11), pp 1084-1095 (https:// doi.org/10.1161/CIRCRESAHA.107.162511).

25. da Silveira, G. D.; Bressan, L. P.; Schmidt, M. E. P.; Molin, T. R. D.; Teixeira, C. A.; Poppi, R. J.; da Silva, J. A. F. J. Solid State Electrochem., 2020, 24 (8), pp 1999-2010 (https://doi.org/10.1007/s10008020-04533-1).

26. Al-Hroub, H.; Alkhawaja, B.; Alkhawaja, E.; Arafat, T. J. Chromatogr. B., 2016, 1009-1010, pp 1-6 (https://doi.org/10.1016/j.jchromb.2015.11.059). 
27. Salem, H.; Aziz, B. E. A. Anal. Chem. Lett., 2020, 10 (3), pp 321-335 (https://doi.org/10.1080/222979 28.2020.1779813).

28. Keizers, P. H. J.; Wiegard, A.; Venhuis, B. J. J. Pharm. Biomed. Anal., 2016, 131, pp 133-139 (https:// doi.org/10.1016/j.jpba.2016.08.027).

29. Sopha, H.; Hocevar, S. B.; Pihlar, B.; Ogorevc, B. Electrochim. Acta, 2012, 60, pp 274-277 (https://doi. org/10.1016/j.electacta.2011.11.049).

30. Lović, J.; Trišović, N.; Antanasijević, J.; Ivić, M. A. J. Electrochem. Sci. Eng., 2018, 8 (2), pp 163-170 (https://doi.org/10.5599/jese.481).

31. Tyszczuk, K.; Korolczuk, M. Bioelectrochemistry, 2010, 78 (2), pp 113-117 (https://doi.org/10.1016/j. bioelechem.2009.08.005).

32. Rouhani, M.; Soleymanpour, A. Microchim. Acta, 2020, 187 (9), 512 (https://doi.org/10.1007/s00604020-04482-6).

33. Batista, E. F.; Sartori, E. R.; Medeiros, R. A.; Rocha-Filho, R. C.; Fatibello-Filho, O. Anal. Lett., 2010, 43 (6), pp 1046-1054 (https://doi.org/10.1080/00032710903491153).

34. Berzas, J. J.; Rodriguez, J.; Castañeda, G.; Villaseñor, M. J. Anal. Chim. Acta, 2000, 417 (2), pp 143148 (https://doi.org/10.1016/S0003-2670(00)00932-6).

35. Staden, R. S.; Staden, J. F. V.; Aboul-Enein, H. Y. J. Solid State Electrochem., 2010, 14 (6), pp 9971000 (https://doi.org/10.1007/s10008-009-0901-7).

36. Özkan, S. A.; Uslu, B.; Zuman, P. Anal. Chim. Acta, 2004, 501 (2), pp 227-233 (https://doi.org/10.1016/j. aca.2003.09.033).

37. Farghali, R. A.; Ahmed, R. A. Int. J. Electrochem. Sci., 2015, 10 (2), pp 1494-1505.

38. Backes, R. S.; Guedes, T. J.; dos Santos, W. T. P.; da Silva, R. A. B. Quim. Nova, 2017, 40 (7), pp 752759 (http://dx.doi.org/10.21577/0100-4042.20170047).

39. Júnior, A. C. V. L.; Luz, R. C. S.; Damos, F. S.; dos Santos, A. S.; Franco, D. L.; dos Santos, W. T. P. J. Braz. Chem. Soc., 2012, 23 (10), pp 1800-1806 (https://doi.org/10.1590/S0103-50532012005000047).

40. Silva-Neto, H. A.; Cardoso, T. M. G.; McMahon, C. J.; Sgobbi, L. F.; Henry, C. S.; Coltro, W. K. T. Analyst, 2021, 146 (11), pp 3463-3473 (https://doi.org/10.1039/d1an00176k).

41. Afonso, A. S.; Uliana, C. V.; Martucci, D. H.; Faria, R. C. Talanta, 2016, 146, pp 381-387 (https://doi. org/10.1016/j.talanta.2015.09.002).

42. Rocha, D. S.; Duarte, L. C.; Silva-Neto, H. A.; Chagas, C. L. S.; Santana, M. H. P.; Antoniosi Filho, N. R.; Coltro, W. K. T. Talanta, 2021, 232, 122408 (https://doi.org/10.1016/j.talanta.2021.122408).

43. da Silva, V. A. O. P.; Tartare, V. A. P.; Kalinke, C.; de Oliveira, P. R.; Bonacin, J. A.; Janegitz, B. C. Quim. Nova, 2020, 43 (9), pp 1312-1319 (http://dx.doi.org/10.21577/0100-4042.20170624).

44. Nicholson, R. S. Anal. Chem., 1965, 37 (11), pp 1351-1355 (https://doi.org/10.1021/ac60230a016).

45. Noviana, E.; McCord, C. P.; Clark, K. M.; Jang, I.; Henry, C. S. Lab Chip, 2020, 20 (1), pp 9-34 (https:// doi.org/10.1039/c9lc00903e).

46. Cumba, L. R.; Foster, C. W.; Brownson, D. A. C.; Smith, J. P.; Iniesta, J.; Thakur, B.; do Carmo, D. R.; Banks, C. E. Analyst, 2016, 141, pp 2791-2799 (https://doi.org/10.1039/c6an00167j).

47. Pimenta, M. A.; Dresselhaus, G.; Dresselhaus, M. S.; Cançado, L. G.; Jorio, A.; Saito, R. Phys. Chem. Chem. Phys., 2007, 9 (11), pp 1276-1291 (https://doi.org/10.1039/b613962k).

48. Dias, A. A.; Chagas, C. L. S.; Silva-Neto, H. A.; Lobo-Junior, E. O.; Sgobbi, L. F.; de Araujo, W. R.; Paixão, T. R. L. C.; Coltro, W. K. T. ACS Appl. Mater. Interfaces, 2019, 11 (43), pp 39484-39492 (https:// doi.org/10.1021/acsami.9b12797).

49. Klunder, K. J.; Nilsson, Z.; Sambur, J. B.; Henry C. S. J. Am. Chem. Soc., 2017, 139 (36), pp 1262312631 (https://doi.org/10.1021/jacs.7b06173).

50. de Araujo, W. R.; Frasson, C. M. R.; Ameku, W. A.; Silva, J. R.; Angnes, L.; Paixão, T. R. L. C. Angew. Chem., 2017, 129 (47), pp 15309-15313 (https://doi.org/10.1002/anie.201708527).

51. Arduini, F.; Cinti, S.; Mazzaracchio, V.; Scognamiglio, V.; Amine, A.; Moscone, D. Biosens. Bioelectron., 2020, 156, 112033 (https://doi.org/10.1016/j.bios.2020.112033). 
52. Santhiago, M.; Strauss, M.; Pereira, M. P.; Chagas, A. S.; Bufon, C. C. B. ACS Appl. Mater. Interfaces, 2017, 9 (13), pp 11959-11966 (https://doi.org/10.1021/acsami.6b15646).

53. Dossi, N.; Petrazzi, S.; Terzi, F.; Toniolo, R.; Bontempelli, G. Talanta, 2019, 199, pp 14-20 (https://doi. org/10.1016/j.talanta.2019.01.126).

54. Maria, J.; Noordin, M. I. J. Therm. Anal. Calorim., 2014, 115 (2), pp 1907-1914 (https://doi.org/10.1007/ s10973-013-3413-8).

55. Moosavi, S. M.; Ghassabian, S. Linearity of Calibration Curves for Analytical Methods: A Review of Criteria for Assessment of Method Reliability. In: Stauffer, M. (Ed.). Calibration and Validation of Analytical Methods - A Sampling of Current Approaches. Intechopen, 2018, Chapter 6, pp 109-127 (https://doi.org/10.5772/intechopen.72932).

56. Sartori, E. R.; Clausen, D. N.; Pires, I. M. R.; Salamanca-Neto, C. A. R. Diam. Relat. Mater., 2017, 77, pp 153-158 (https://doi.org/10.1016/j.diamond.2017.07.001).

57. Tyszczuk, K.; Korolczuk, M. Bioelectrochemistry, 2010, 78 (2), pp 113-117 (https://doi.org/10.1016/j. bioelechem.2009.08.005).

\section{Supplementary Material}

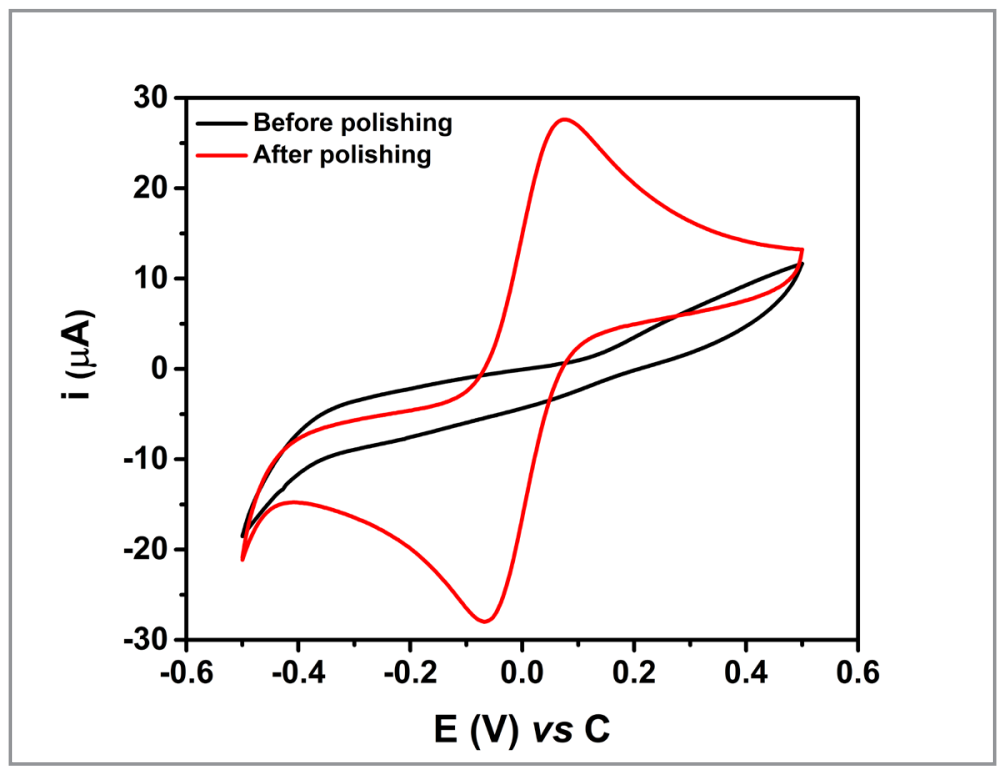

Figure S1. Cyclic voltammograms recorded in presence of $1.0 \mathrm{mmol} \mathrm{L}^{-1}\left[\mathrm{Fe}(\mathrm{CN})_{6}\right]^{4-3-}$ prepared in $\mathrm{KCl} 0.1 \mathrm{~mol} \mathrm{~L}^{-1}$ using electrode without sanding and after polishing process with sandpaper. Electrochemical conditions: $50 \mathrm{mV} \mathrm{s}^{-1}$ ranging from -0.5 to $0.5 \mathrm{~V}$ vs $\mathrm{C}$. 

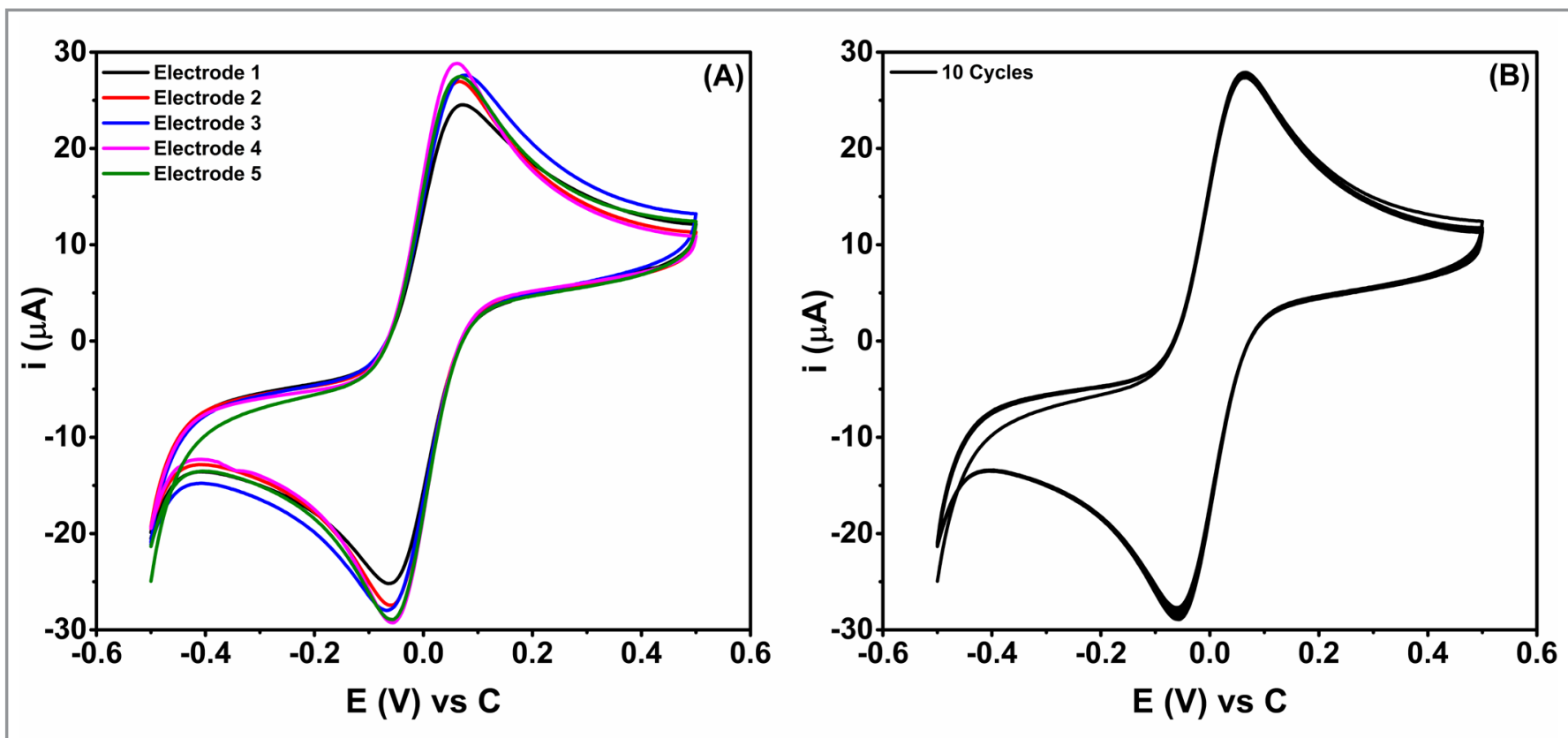

Figure S2. Cyclic voltammograms responses obtained for $(A)$ reproducibility and $(B)$ repeatability electrochemical experiments.

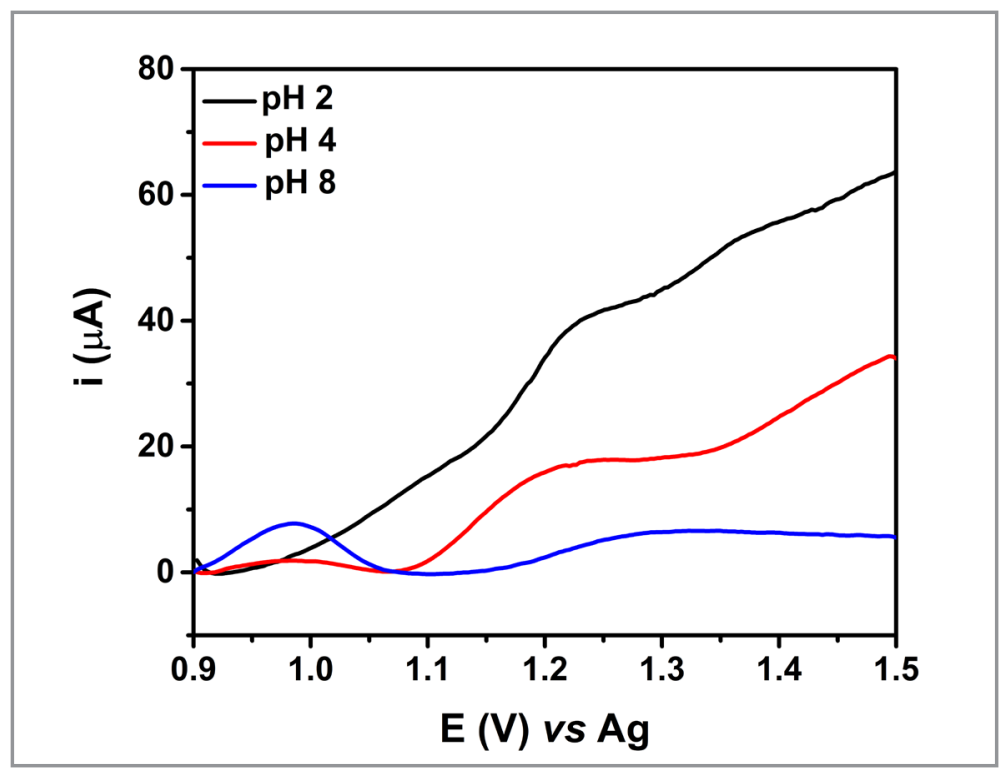

Figure S3. Square wave voltammograms measurements of sildenafil citrate involving the optimization study of buffer solution. Buffer solution conditions: $0.03 \mathrm{~mol} \mathrm{~L}^{-1}$ Britton-Robinson in presence of $500 \mu \mathrm{mol} \mathrm{L} \mathrm{L}^{-1}$ sildenafil citrate. Electrochemical conditions: $10 \mathrm{~Hz}$ frequency, $0.025 \mathrm{~V}$ amplitude and $0.003 \mathrm{~V}$ step ranging from 0.9 to $1.5 \mathrm{~V}$ vs Ag. 


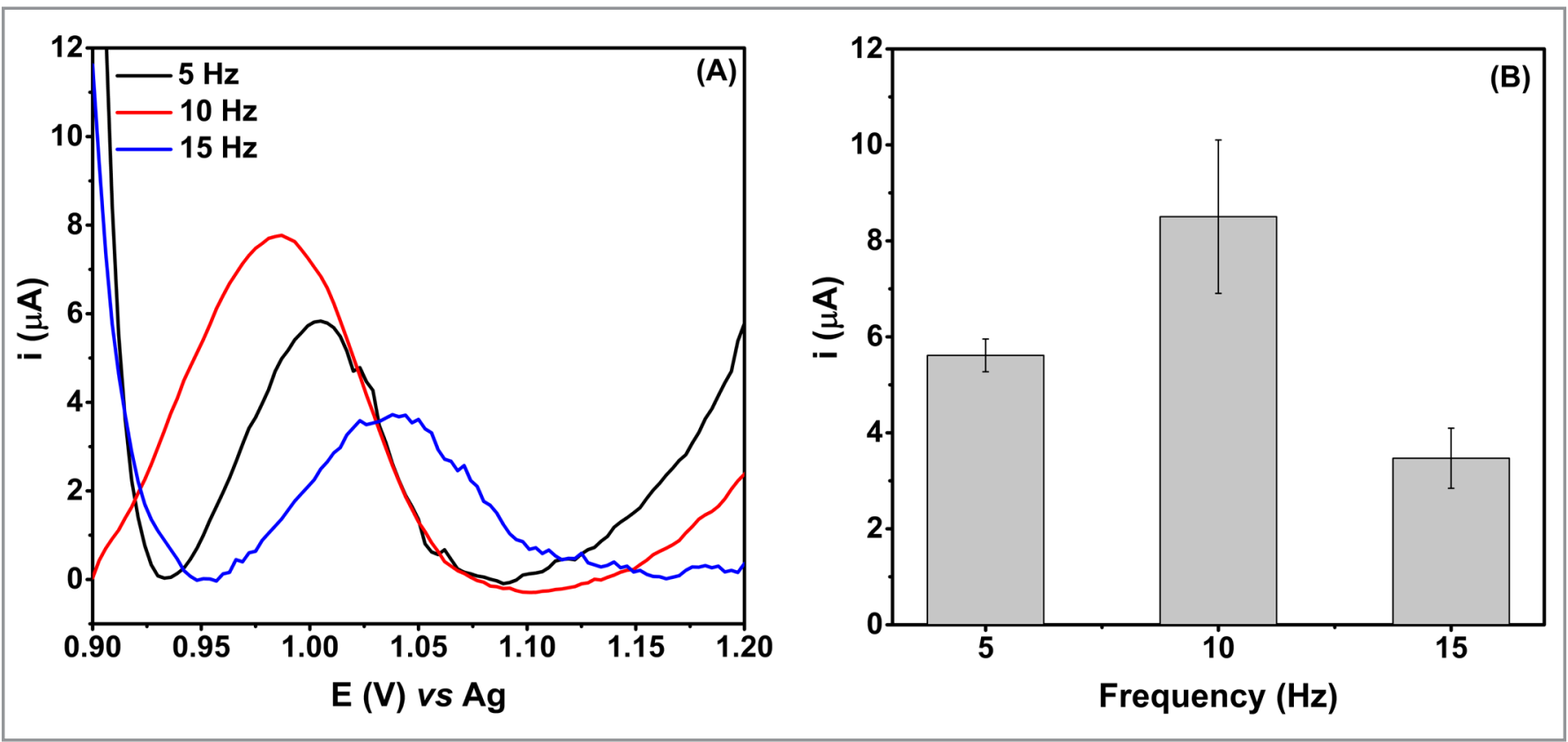

Figure S4. (A) SWV experiments of the frequency parameter optimization involving the sildenafil citrate oxidation. Buffer solution condition: $0.03 \mathrm{~mol} \mathrm{~L}^{-1}$ Britton-Robinson $(\mathrm{pH}=8)$. (B) Peak current signal of sildenafil citrate oxidation. Optimized electrochemical conditions: $0.025 \mathrm{~V}$ amplitude, $0.003 \mathrm{~V}$ step and potential range 0.9 to $1.5 \mathrm{~V}$.
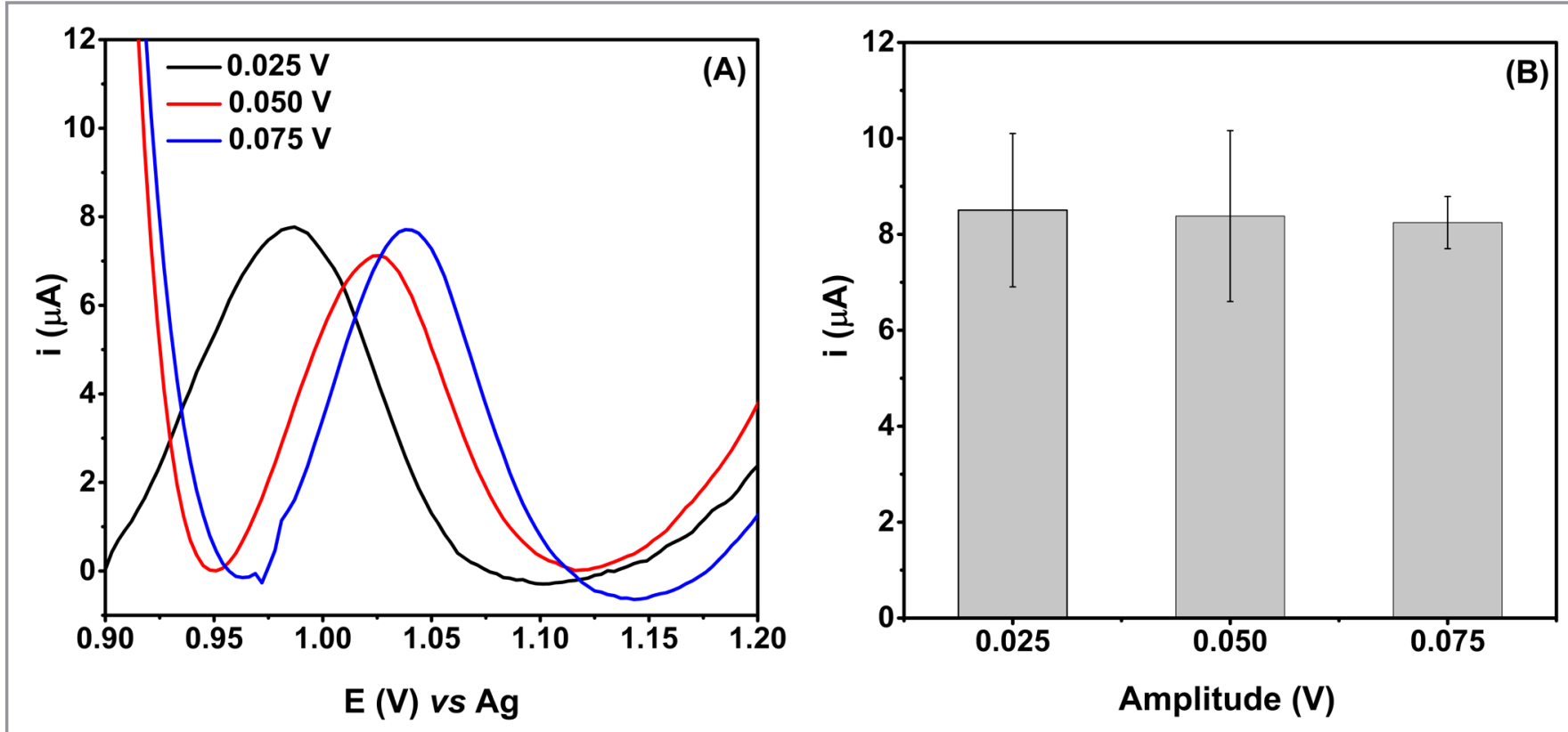

Figure S5. (A) SWV experiments of the amplitude parameter optimization involving the sildenafil citrate oxidation. (B) Peak current responses of sildenafil citrate oxidation. Fixed SWV conditions: $0.003 \mathrm{~V}$ step, $10 \mathrm{~Hz}$ frequency ranging from 0.9 to $1.5 \mathrm{~V} v s \mathrm{Ag}$. 


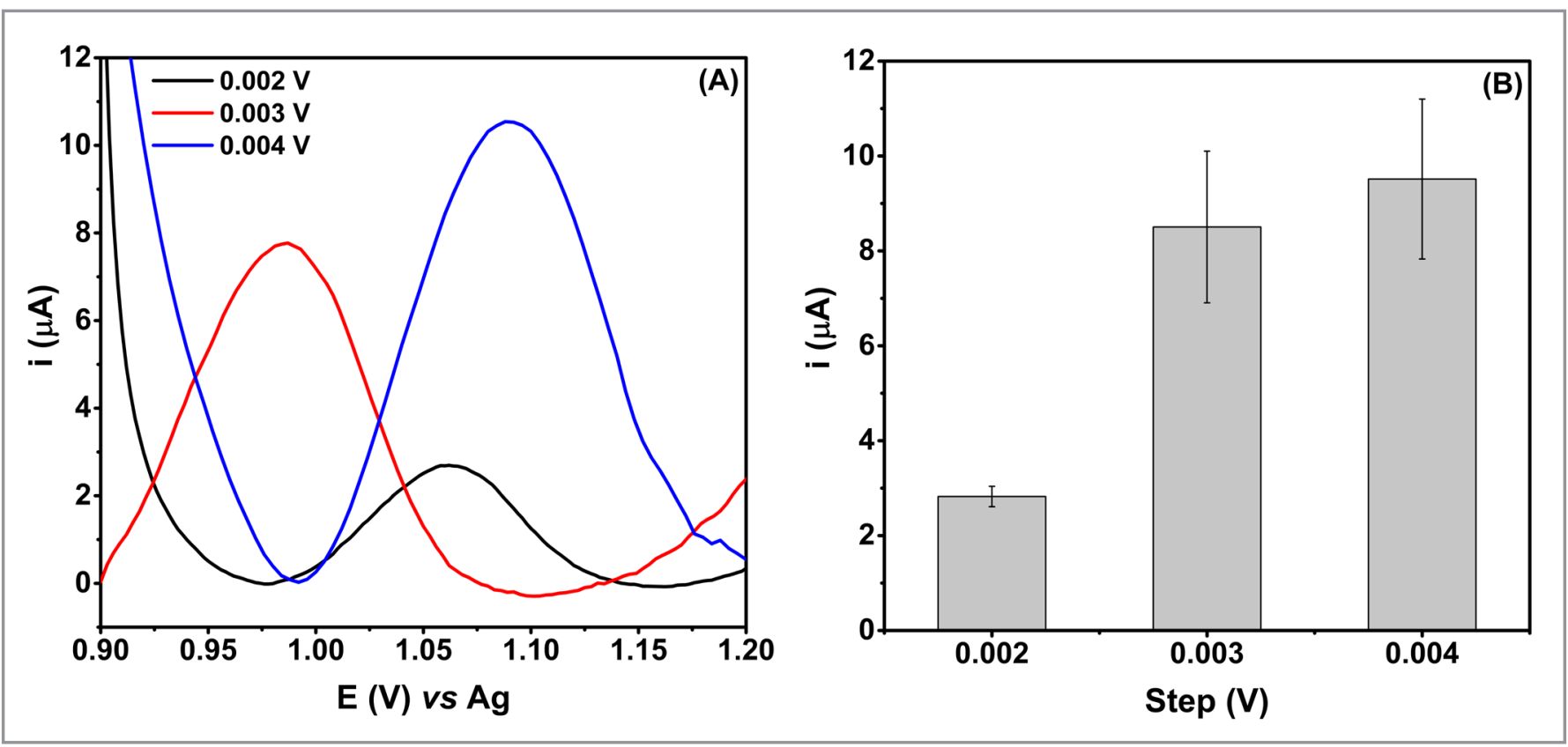

Figure S6. (A) SWV experiments of the step parameter optimization involving the sildenafil citrate oxidation. (B) Peak current responses of sildenafil citrate oxidation. Fixed SWV conditions: $0.025 \mathrm{~V}$ amplitude, $10 \mathrm{~Hz}$ frequency ranging from 0.9 to $1.5 \mathrm{~V} v s \mathrm{Ag}$.

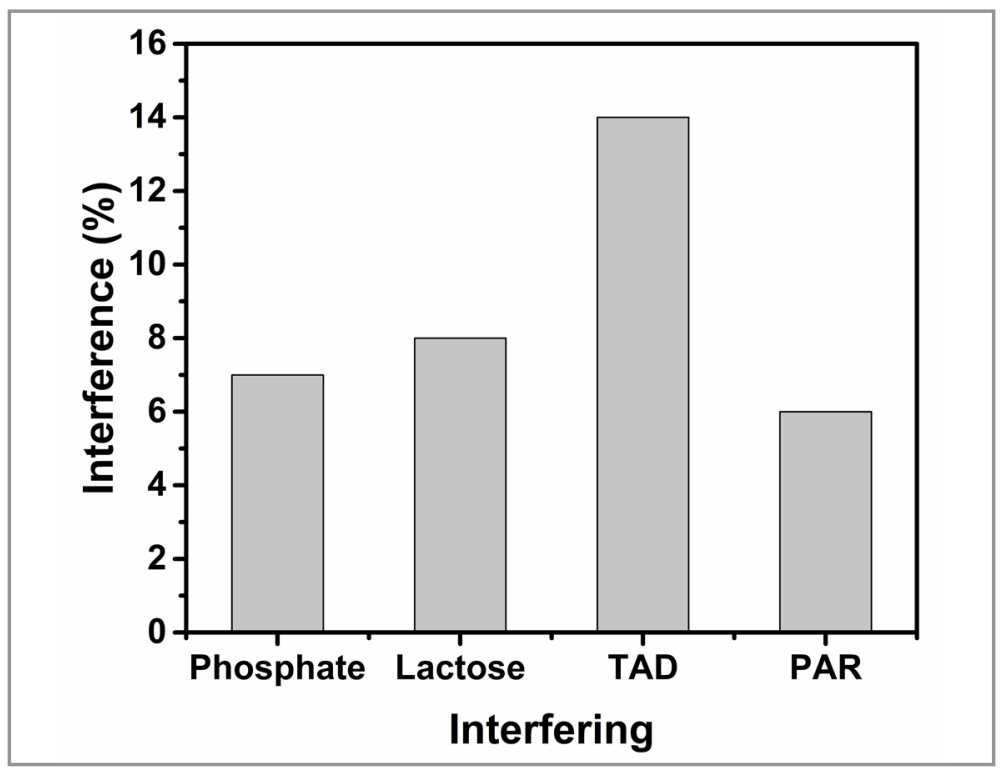

Figure S7. Obtained electrochemical results to sildenafil oxidation realized in presence of possible interfering species. 
Rocha, D. S.; Silva-Neto, H. A.; Oliveira, L. C.; Souza, S. G. G.; Santana, M. H. P.; Coltro, W. K. T.

Table SI. Comparison of the type of electrode, electrochemical method, linear range and limit of detection (LOD) for sildenafil citrate detection

\begin{tabular}{llcccc}
\hline Electrode & Sample & Method & Linear range $\left(\mathrm{mol} \mathrm{L}^{-1}\right)$ & LOD (mol L-1) & Reference \\
\hline Glassy carbon & $\begin{array}{l}\text { Pharmaceutical } \\
\text { formulations }\end{array}$ & SWV & $\begin{array}{c}6.0 \times 10^{-6}-3.0 \times 10^{-4} \text { and } \\
4.0 \times 10^{-6}-3.0 \times 10^{-4}\end{array}$ & $\begin{array}{c}6.3 \times 10^{-7} \text { and } \\
1.1 \times 10^{-6}\end{array}$ & [1] \\
$\begin{array}{l}\text { Boron-doped } \\
\text { diamond electrode }\end{array}$ & $\begin{array}{l}\text { Pharmaceutical } \\
\text { formulations }\end{array}$ & DPV & $7.3 \times 10^{-7}-7.3 \times 10^{-6}$ & $6.4 \times 10^{-7}$ & [2] \\
$\begin{array}{l}\text { Scrren-printed } \\
\text { carbon }\end{array}$ & $\begin{array}{l}\text { Pharmaceutical } \\
\text { formulations }\end{array}$ & BIA & $3.0 \times 10^{-6}-21 \times 10^{-6}$ & $5.2 \times 10^{-8}$ & [3] \\
$\begin{array}{l}\text { Screen-printed } \\
\text { glassy carbon }\end{array}$ & $\begin{array}{l}\text { Pharmaceutical } \\
\text { formulations }\end{array}$ & SWV & $1.0 \times 10^{-6}-1.4 \times 10^{-5}$ & $5.5 \times 10^{-8}$ & [4] \\
$\begin{array}{l}\text { Screen-printed } \\
\text { carbon electrode }\end{array}$ & $\begin{array}{l}\text { Pharmaceutical } \\
\text { formulations and } \\
\text { adulterated tablet }\end{array}$ & SWV & $1.0 \times 10^{-6}-20 \times 10^{-6}$ & $2.0 \times 10^{-7}$ & This study \\
\hline
\end{tabular}

\section{REFERENCES}

1. Özkan, S. A.; Uslu, B.; Zuman, P. Anal. Chim. Acta, 2004, 501, pp 227-233

(https://doi.org/10.1016/j.aca.2003.09.033).

2. Batista, É. F.; Sartori, E. R.; Medeiros, R. A.; Rocha-Filho, R. C.; Fatibello-Filho, O. Anal. Lett., 2010, 43 (6), pp 1046-1054 (https://doi.org/10.1080/00032710903491153.).

3. Backes, R. S.; Guedes, T. J.; dos Santos, W. T. P.; da Silva, R. A. B. Quim. Nova, 2013, 40 (7), pp 1248-1255 (http://dx.doi.org/10.21577/0100-4042.20170047).

4. Farghali, R. A.; Ahmed, R. A. Int. J. Electrochem. Sci., 2012, 7 (12), pp 13008-13019. 